\title{
Enantioselective Synthesis of Five-Membered-Ring Atropisomers with a Chiral Rh(III) Complex
}

\author{
Saad Shaaban, Houhua Li, Felix Otte, Carsten Strohmann, Andrey P. Antonchick,* \\ and Herbert Waldmann*
}

Cite This: Org. Lett. 2020, 22, 9199-9202

Read Online

\section{ACCESS | \\ 山ll Metrics \& More \\ Article Recommendations \\ Supporting Information}
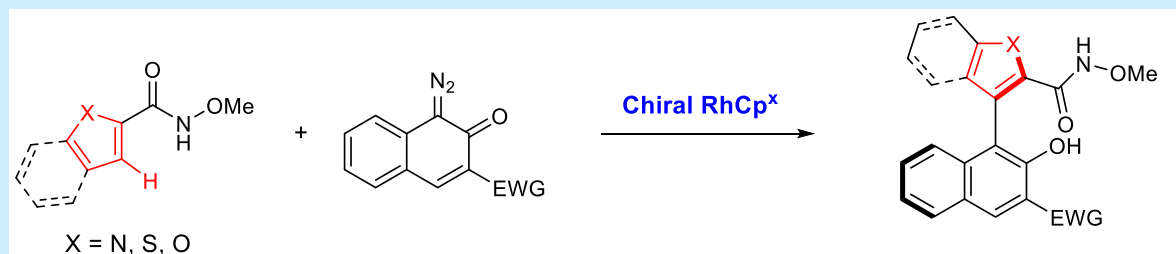

29 examples

up to $96 \%$ yield and $94 \%$ ee

ABSTRACT: Axially chiral atropisomeric compounds are widely applied in asymmetric catalysis and medicinal chemistry, and efficient methods for their synthesis are in high demand. This applies in particular to atropisomers derived from five-membered aromatic rings because their lower barrier for rotation among the biaryl axis limits their asymmetric synthesis. We report here an enantioselective $\mathrm{C}-\mathrm{H}$ functionalization method using our chiral RhJas $\mathrm{Cp}$ complex for the synthesis of the biaryl atropisomer types that can be accessed from three different five-membered-ring heterocycles.

\begin{abstract}
A xially chiral atropisomers have found widespread applicaAtion in diverse areas of investigation, in particular asymmetric synthesis and medicinal chemistry, and consequently, methods for their efficient synthesis are in high demand. ${ }^{1}$ Attention has been mostly focused on sixmembered-ring biaryl axis atropisomers, ${ }^{2}$ but atropisomers formed from five-membered rings have been infrequently explored (Scheme 1a). In these cases, the lower barrier for rotation among the biaryl axis limits both their asymmetric synthesis and their applicability. ${ }^{3}$ Carbazole-, indole-, and pyrrole-derived atropisomers with mostly a $\mathrm{C}-\mathrm{N}$ axis, but also $\mathrm{C}-\mathrm{C}$ axis, have been isolated from natural sources (Scheme 1b). ${ }^{4} \mathrm{~A}$ few synthesized chiral five-membered-ring atropisomer ligands have also been employed in asymmetric catalysis (Scheme 1b). Five-membered-ring atropisomers have been synthesized by means of transition metal-catalyzed cross coupling reactions ${ }^{5}$ (Scheme 1c, left), organo-catalyzed asymmetric arylations ${ }^{6}$ (Scheme $1 \mathrm{c}$, right), and the establishment of the biaryl axis via construction of one of the rings. ${ }^{7}$ In addition, enantioselective $\mathrm{C}-\mathrm{H}$ functionalization using chiral $\mathrm{Cp}^{\mathrm{x}}$ ligands has been employed as an alternative strategy to access atropisomers. ${ }^{8}$ Thus, Heller et al. reported a Co-catalyzed enantioselective synthesis of axially chiral biaryls by means of $[2+2+2]$ cycloaddition reactions, ${ }^{9}$ You et al. described an enantioselective dehydrogenative Heck coupling of biaryls with alkenes, ${ }^{10}$ and Cramer et al. achieved an Ir-catalyzed synthesis of axially chiral biaryl phosphines using diazonaphthoquinones. ${ }^{11}$ We have described an intramolecular $\mathrm{C}-\mathrm{H}$ functionalization of
\end{abstract}

aromatic compounds with alkynes forming axially chiral 4arylisoquinolones catalyzed by chiral $\mathrm{Rh} J a s \mathrm{Cp}$ complexes, ${ }^{12}$ and $\mathrm{Li}$ et al. recently reported the use of chiral $\mathrm{RhCp}^{\mathrm{x}}$ complexes in the synthesis of axially chiral biindolyls. ${ }^{13}$ To the best of our knowledge, there is no general enantioselective method that enables the construction of atropisomers containing a fivemembered aromatic ring (furans, thiophenes, and pyrroles). Herein, we report the RhJasCp-catalyzed enantioselective synthesis of these five-membered-ring atropisomers via direct $\mathrm{C}-\mathrm{H}$ functionalization with 1-diazonaphthoquinones (Scheme 1c, bottom).

To establish the methodology, we investigated coupling of 2amido-benzothiophene $1 a^{14}$ and 1-diazonaphthoquinone $2 a$ as model substrates using various $\mathrm{RhJasCp}$ catalysts. As shown in Table 1, Rh1 led to the formation of desired product $3 \mathbf{a}$ in low yield and poor enantiomeric ratio (entry 1 ), whereas $\mathbf{R h} 2$ gave the corresponding product in higher yield and better enantiomeric ratio (entry 2). Screening of a variety of solvents demonstrated that 1,4-dioxane was the best (entries 2-7), and variation of the catalysts with strict temperature control (entries 8-12) showed that $\mathbf{R h} 3$ gave the desired product in excellent

Received: October 7, 2020

Published: November 13, 2020 
Scheme 1. (A) Comparison between Five-Membered-Ring and Six-Membered-Ring Atropisomers, (B) Selected Examples of Natural Products and Synthetic Chiral Ligands, and (C) General Approaches for Biaryl Synthesis and a Proposed Strategy Using Chiral RhJasCp Complexes

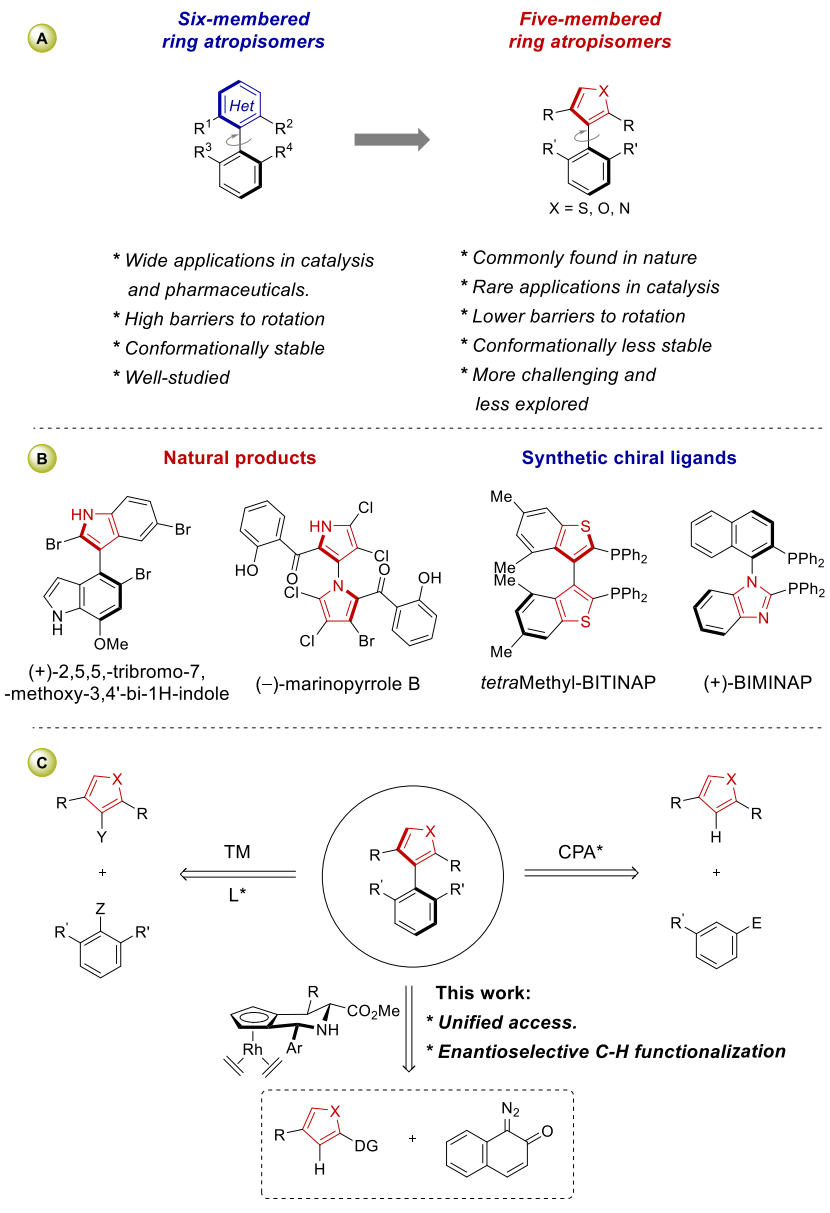

yield and with very good enantiomeric ratio (entry 11). It should be noted that the temperature moderately influences the enantioselectivity (entries 8, 11, and 12).

After having identified suitable reaction conditions, we investigated the scope for the transformation of thiophenes and benzothiophenes (Scheme 2). A substituent at position C-4 of the benzothiophenes led to an increase in enantioselectivity. Thus, 4-fluoro and chloro substituents $(3 c-3 g)$ afforded the corresponding biaryl derivatives in high yields and excellent enantiomeric ratios. In addition, the presence of electrondonating (3f) and electron-withdrawing (3b) groups was tolerated and the desired products were formed in good yields and very appreciable enantioselectivities. Thiophene (3i) was obtained in high yield; however, the compound racemized very quickly. We attributed this to the lack of steric hindrance allowing the rotation barrier to remain low. To overcome this problem, sterically demanding substituents were incorporated at position C-4 of the thiophene coupling partner, and the corresponding thiophene atropisomers were formed in very good yields and high enantiomeric excesses $(3 k-3 p)$. We note that bromo derivative (3n) may open up further opportunities to elaborate structure, e.g., via $\operatorname{Pd}(0)$ chemistry. Slow evaporation of product $3 p$ afforded crystals suitable for X-ray diffraction analysis, which allowed us to unambiguously confirm the structure. Measuring several crystals provided the same
Table 1. Optimization of Conditions for the Enantioselective Synthesis of Five-Membered-Ring Atropoisomeric Benzothiophene $3 \mathrm{a}^{a}$

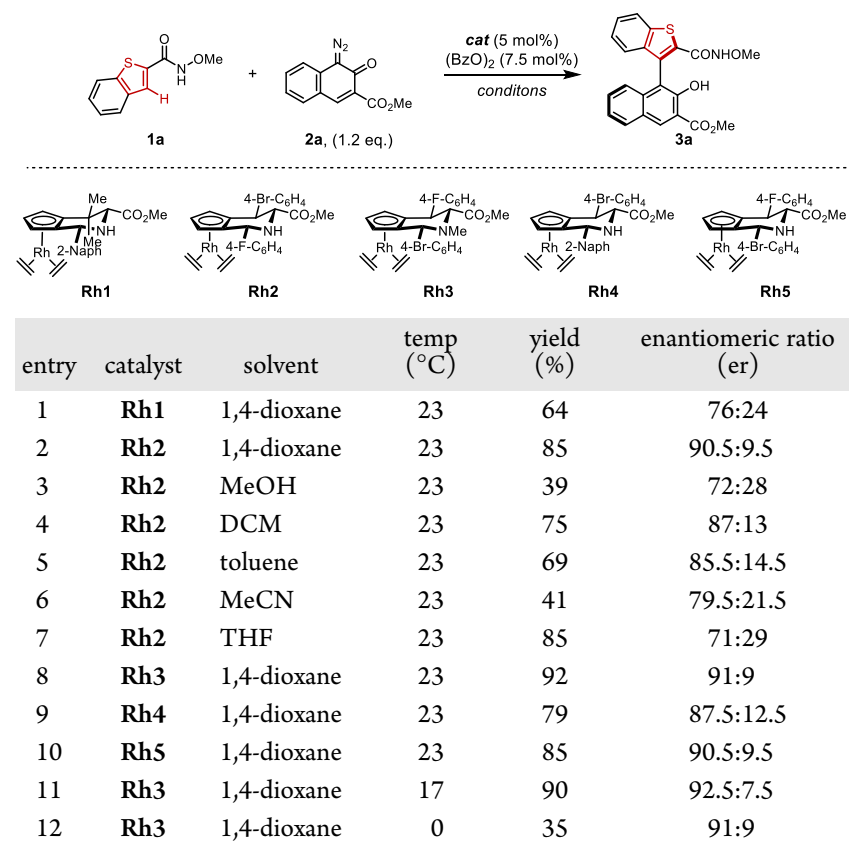

${ }^{a}$ Reactions were run for $36 \mathrm{~h}$. Yields were determined for isolated products. Values of ee were determined using chiral HPLC.

Scheme 2. Scope of the Enantioselective Synthesis of FiveMembered-Ring Atropoisomeric Thiophenes and Benzothiophenes

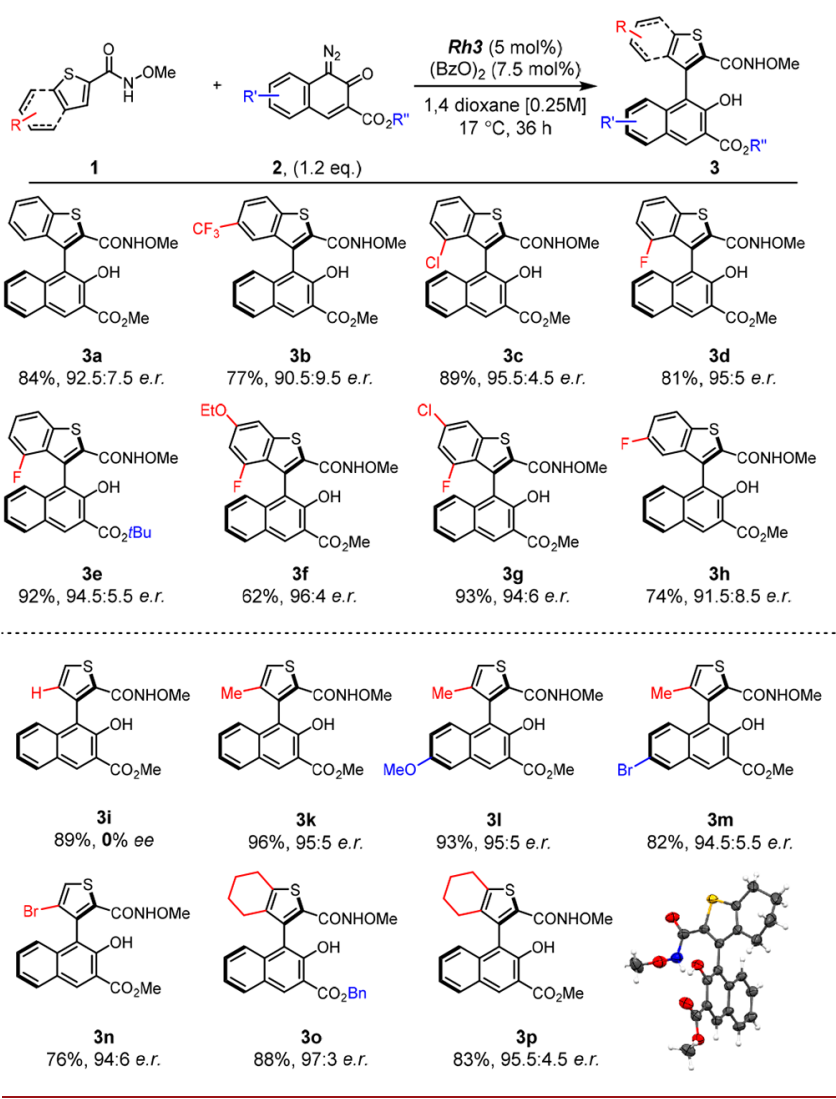

absolute configuration ( $a R$ ) (CCDC 1994612; see the Supporting Information for more details). 
To further explore the applicability of the method, the scope for analogous transformations employing benzofurans and furans was investigated (Scheme 3). Benzofuran afforded

Scheme 3. Scope of the Enantioselective Synthesis of FiveMembered-Ring Atropoisomeric Furans and Benzofurans

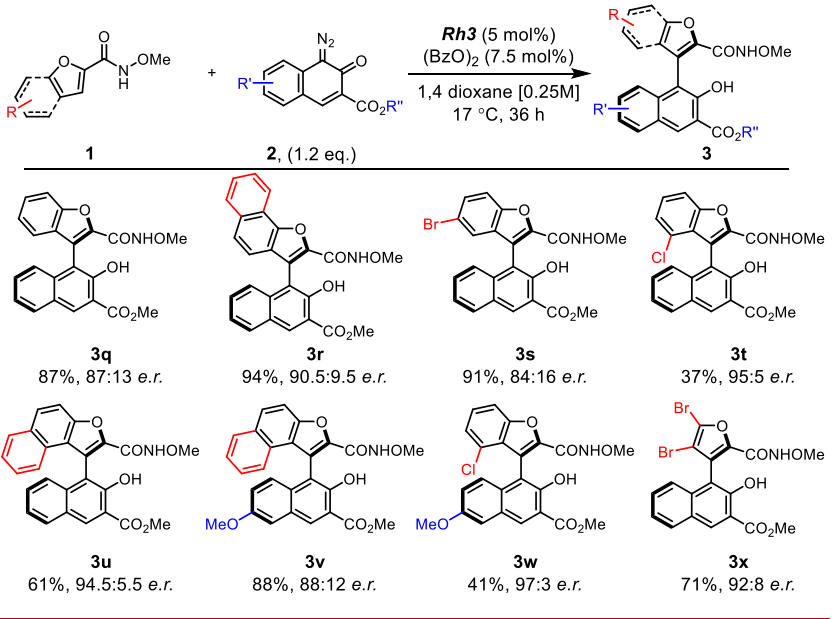

desired product $\mathbf{3 q}$ in good yield albeit with lower enantioselectivity. Increasing the steric bulk at position C-4 led to formation of the desired benzofuran biaryl atropisomers in good yields and high enantioselectivities $(3 t-3 w)$. We note that high reactivity with good enantioselectivity was also observed with a bromo-substituted furan derivative $(3 \mathbf{x})$.

The orienting exploration of indoles and pyrroles in this transformation revealed that indoles with an unprotected $\mathrm{NH}$ group and a directing group at position $\mathrm{C}-2$ are not reactive under the employed conditions. Introduction of a variety of substituents at the nitrogen atom did not substantially improve this situation (see the Supporting Information for more details). Fortunately, installation of the directing group on the nitrogen ${ }^{15}$ afforded the desired products in very good yield and moderate to high ee values under the optimized reaction conditions. Exploration of the reaction scope revealed that indoles bearing both electron-donating and electron-withdrawing groups were tolerated and yielded the desired 2-indolo-naphthaline atropisomers $(\mathbf{4 b}-\mathbf{4 h})$ in good yields and good enantioselectivities (Scheme 4).

On the basis of previous studies, the mechanism shown in Scheme 5 for rationalizing the observed transformation appears to be plausible. ${ }^{16}$ The reaction begins with an oxidative addition of active $\mathrm{Rh}$ (III) complex I to give five-membered-ring rhodacyle II. Insertion of the diazonaphthoquinone affords intermediate III, which upon loss of nitrogen $\left(\mathrm{N}_{2}\right)$ yields $\mathrm{Rh}-$ carbene intermediate IV. This intermediate undergoes 1,2migration, followed by subsequent reductive elimination yielding chiral compound VI. Finally, aromatization (point to axis chirality transfer) furnishes final biaryl atropisomer 3 .

In conclusion, we have developed an enantioselective $\mathrm{C}-\mathrm{H}$ functionalization method giving access to the biaryl atropisomer types that can be accessed from three different five-memberedring heterocycle classes. The method enabled a straightforward synthesis of (benzo)furano, (benzo)thiopheno, and indolo atropoisomers in high yields and high enantioselectivity. In light of the challenging synthesis of these five-membered-ring atropoisomeric products in general, we anticipate that this practical, enantioselective direct $\mathrm{C}-\mathrm{H}$ functionalization meth-
Scheme 4. Scope of the Enantioselective Synthesis of FiveMembered-Ring Atropoisomeric Indoles

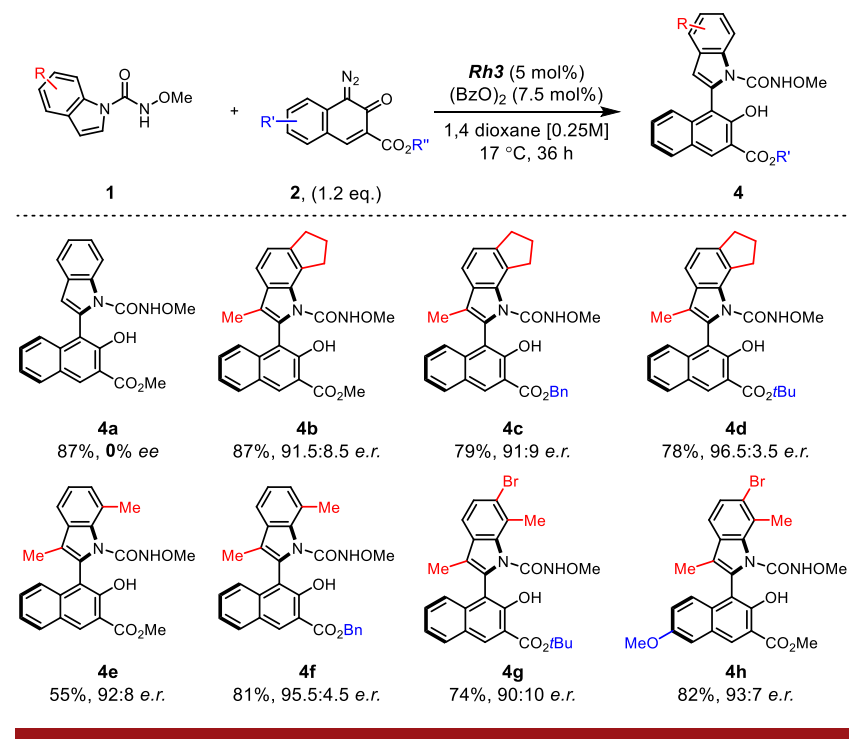

Scheme 5. Proposed Reaction Mechanism

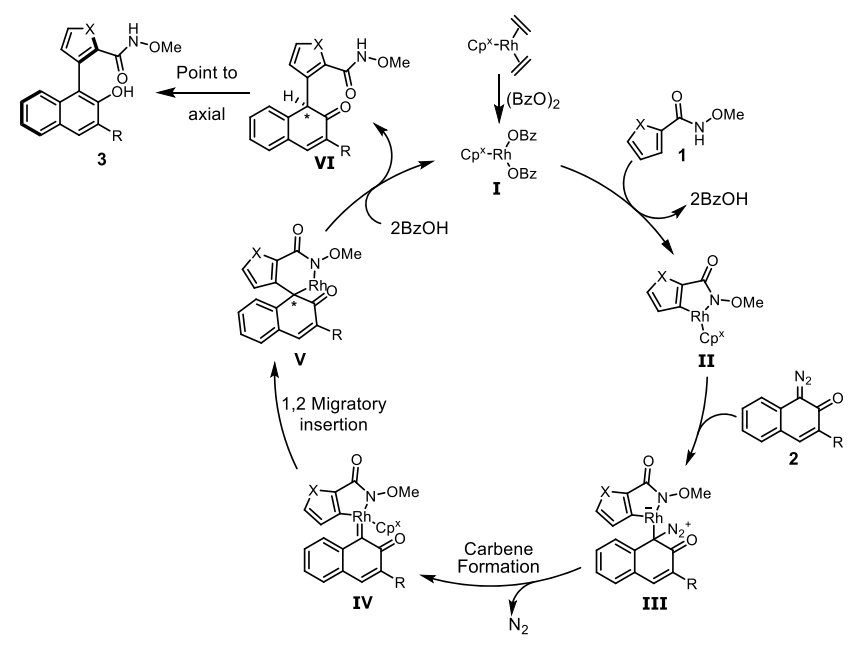

odology may find widespread interest and application in various areas of science.

\section{ASSOCIATED CONTENT}

\section{Supporting Information}

The Supporting Information is available free of charge at https://pubs.acs.org/doi/10.1021/acs.orglett.0c03355.

Experimental procedures and characterization data for all new compounds and computational details (PDF)

\section{Accession Codes}

CCDC 1994612 contains the supplementary crystallographic data for this paper. These data can be obtained free of charge via www.ccdc.cam.ac.uk/data_request/cif, or by emailing data_ request@ccdc.cam.ac.uk, or by contacting The Cambridge Crystallographic Data Centre, 12 Union Road, Cambridge CB2 1EZ, UK; fax: +44 1223336033. 


\section{AUTHOR INFORMATION}

\section{Corresponding Authors}

Andrey P. Antonchick - Max-Planck-Institute of Molecular Physiology, Department of Chemical Biology, 44227 Dortmund, Germany; Technical University Dortmund, Faculty of Chemical Biology, 44227 Dortmund, Germany; () orcid.org/0000-0003-0435-9443;

Email: andrey.antonchick@mpi-dortmund.mpg.de

Herbert Waldmann - Max-Planck-Institute of Molecular Physiology, Department of Chemical Biology, 44227 Dortmund, Germany; Technical University Dortmund, Faculty of Chemical Biology, 44227 Dortmund, Germany; (1) orcid.org/0000-0002-9606-7247;

Email: herbert.waldmann@mpi-dortmund.mpg.de

\section{Authors}

Saad Shaaban - Max-Planck-Institute of Molecular Physiology, Department of Chemical Biology, 44227 Dortmund, Germany

Houhua Li - Max-Planck-Institute of Molecular Physiology, Department of Chemical Biology, 44227 Dortmund, Germany

Felix Otte - Technical University Dortmund, Department of Inorganic Chemistry, 44227 Dortmund, Germany

Carsten Strohmann - Technical University Dortmund, Department of Inorganic Chemistry, 44227 Dortmund, Germany

Complete contact information is available at: https://pubs.acs.org/10.1021/acs.orglett.0c03355

Notes

The authors declare no competing financial interest.

\section{ACKNOWLEDGMENTS}

This work was supported by the Max-Planck-Gesellschaft. S.S. thanks the Alexander von Humboldt Foundation for funding. H.L. is grateful to the Swiss National Science Foundation (SNSF) for an Early Postdoc. Mobility fellowship (P2GEP2_168250).

\section{REFERENCES}

(1) (a) Bringmann, G.; Price Mortimer, A. J.; Keller, P. A.; Gresser, M. J.; Garner, J.; Breuning, M. Angew. Chem., Int. Ed. 2005, 44, 5384. (b) LaPlante, S. R.; Fader, L. D.; Fandrick, K. R.; Fandrick, D. R.; Hucke, O.; Kemper, R.; Miller, S. P. F.; Edwards, P. J. J. Med. Chem. 2011, 54, 7005. (c) Kumarasamy, E.; Raghunathan, R.; Sibi, M. P.; Sivaguru, J. Chem. Rev. 2015, 115, 11239.

(2) (a) Loxq, P.; Manoury, E.; Poli, R.; Deydier, E.; Labande, A. Coord. Chem. Rev. 2016, 308, 131. (b) Wang, Y.; Tan, B. Acc. Chem. Res. 2018, 51, 534. (c) Mancinelli, M.; Bencivenni, G.; Pecorari, D.; Mazzanti, A. Eur. J. Org. Chem. 2020, 2020, 4070.

(3) (a) Bonne, D.; Rodriguez, J. Chem. Commun. 2017, 53, 12385. (b) Bonne, D.; Rodriguez, J. Eur. J. Org. Chem. 2018, 2018, 2417. (c) Li, T.-Z.; Liu, S.-J.; Tan, W.; Shi, F. Chem. - Eur. J. 2020, DOI: 10.1002/ chem.202001397.

(4) (a) Norton, R. S.; Wells, R. J. J. Am. Chem. Soc. 1982, 104, 3628. (b) Hughes, C. C.; Prieto-Davo, A.; Jensen, P. R.; Fenical, W. Org. Lett. 2008, 10, 629. (c) Schneider, P.; Schneider, G. Chem. Commun. 2017, $53,2272$.

(5) (a) He, C.; Hou, M.; Zhu, Z.; Gu, Z. ACS Catal. 2017, 7, 5316. (b) Yamaguchi, K.; Yamaguchi, J.; Studer, A.; Itami, K. Chem. Sci. 2012, 3, 2165. (c) Nishimoto, Y.; Kondo, H.; Yamaguchi, K.; Yokogawa, D.; Yamaguchi, J.; Itami, K.; Irle, S. J. Org. Chem. 2017, 82, 4900. (d) Zhang, S.; Yao, Q.-J.; Liao, G.; Li, X.; Li, H.; Chen, H.-M.; Hong, X.; Shi, B.-F. ACS Catal. 2019, 9, 1956. (e) Nguyen, Q.; Guo, S.; Royal, T.; Baudoin, O.; Cramer, N. J. Am. Chem. Soc. 2020, 142, 2161.
(6) (a) Zhang, H.-H.; Wang, C.-S.; Li, C.; Mei, G.-J.; Li, Y.; Shi, F. Angew. Chem., Int. Ed. 2017, 56, 116. (b) Qi, L.; Mao, J.; Zhang, J.; Tan, B. Nat. Chem. 2018, 10, 58. (c) Zhu, S.; Chen, Y.-H.; Wang, Y.-B.; Yu, P.; Li, S.-Y.; Xiang, S.-H.; Wang, J.-Q.; Xiao, J.; Tan, B. Nat. Commun. 2019, 10, 4268. (d) Chatterjee, S.; Bhattacharjee, P.; Butterfoss, G. L.; Achari, A.; Jaisankar, P. RSC Adv. 2019, 9, 22384. (e) Zheng, S.; Wang, Q.; Zhu, J. Angew. Chem., Int. Ed. 2019, 58, 1494. (f) Zheng, S.; Wang, Q.; Zhu, J. Angew. Chem., Int. Ed. 2019, 58, 9215. (g) Jiang, F.; Chen, K.W.; Wu, P.; Zhang, Y.-C.; Jiao, Y.; Shi, F. Angew. Chem., Int. Ed. 2019, 58, 15104. (h) Lu, S.; Ong, J.-Y.; Yang, H.; Poh, S.-B.; Liew, X.; Seow, C. S. D.; Wong, M.; Zhao, Y. J. Am. Chem. Soc. 2019, 141, 17062.

(7) (a) Wang, D.; Tong, X. Org. Lett. 2017, 19, 6392. (b) Raut, V. S.; Jean, M.; Vanthuyne, N.; Roussel, C.; Constantieux, T.; Bressy, C.; Bugaut, X.; Bonne, D.; Rodriguez, J. J. Am. Chem. Soc. 2017, 139, 2140.

(8) (a) Newton, C. G.; Kossler, D.; Cramer, N. J. Am. Chem. Soc. 2016, 138, 3935. (b) Yoshino, T.; Satake, S.; Matsunaga, S. Chem. - Eur. J. 2020, 26, 7346. (c) Shaaban, S.; Davies, C.; Waldmann, H. Eur. J. Org. Chem. 2020, 6512 DOI: 10.1002/ejoc.202000752.

(9) (a) Gutnov, A.; Heller, B.; Fischer, C.; Drexler, H.-J.; Spannenberg, A.; Sundermann, B.; Sundermann, C. Angew. Chem., Int. Ed. 2004, 43, 3795. (b) Hapke, M.; Kral, K.; Fischer, C.; Spannenberg, A.; Gutnov, A.; Redkin, D.; Heller, B. J. Org. Chem. 2010, $75,3993$.

(10) (a) Zheng, J.; You, S.-L. Angew. Chem., Int. Ed. 2014, 53, 13244. (b) Zheng, J.; Cui, W.-J.; Zheng, C.; You, S.-L. J. Am. Chem. Soc. 2016, 138,5242 .

(11) Jang, Y.-S.; Woźniak, Ł; Pedroni, J.; Cramer, N. Angew. Chem., Int. Ed. 2018, 57, 12901.

(12) (a) Jia, Z.-J.; Merten, C.; Gontla, R.; Daniliuc, C. G.; Antonchick, A. P.; Waldmann, H. Angew. Chem., Int. Ed. 2017, 56, 2429. (b) Shan, G.; Flegel, J.; Li, H.; Merten, C.; Ziegler, S.; Antonchick, A. P.; Waldmann, H. Angew. Chem., Int. Ed. 2018, 57, 14250. (c) Li, H.; Yan, X.; Zhang, J.; Guo, W.; Jiang, J.; Wang, J. Angew. Chem., Int. Ed. 2019, 58,6732 .

(13) (a) Tian, M.; Bai, D.; Zheng, G.; Chang, J.; Li, X. J. Am. Chem. Soc. 2019, 141, 9527. (b) Wang, F.; Qi, Z.; Zhao, Y.; Zhai, S.; Zheng, G.; Mi, R.; Huang, Z.; Zhu, X.; He, X.; Li, X. Angew. Chem., Int. Ed. 2020, 59,13288 .

(14) Wang, D.-H.; Wasa, M.; Giri, R.; Yu, J.-Q. J. Am. Chem. Soc. 2008, $130,7190$.

(15) Chen, X.; Yang, S.; Li, H.; Wang, B.; Song, G. ACS Catal. 2017, 7, 2392.

(16) (a) Chan, W.; Lo, S.; Zhou, Z.; Yu, W. J. Am. Chem. Soc. 2012, 134, 13565. (b) Liu, Z.; Wu, J.; Yang, S. Org. Lett. 2017, 19, 5434. (c) Ghosh, B.; Biswas, A.; Chakraborty, S.; Samanta, R. Chem. - Asian J. 2018, 13, 2388. 